\title{
КОМПЕНСАЦІЯ ЛІНІЙНОГО ЗБУРЕННЯ СИСТЕМИ СТАБІЛІЗАЦІЇ РАКЕТИ
}

\author{
В. В. Авдєєв
}

\section{Дніпровський національний університет імені Олеся Гончара}

Для збуреного руху в одній площині з урахуванням інерції виконавчого пристрою встановлено зв'язок визначеного методом модального управління закону регулювання 3 матрицями похибок. Корені характеристичного полінома згідно зі схемою Баттерворта рівномірно розміщені на півколі заданого радіусу. Результати можуть бути використані при розробці системи як альтернативний варіант визначення закону регулювання, виходячи із вимог до показників точності.

Ключові слова: закон регулювання, модальне управління, точність стабілізації.

For disturbed motion in one plane with taking in account the inertia of an executive device the connection between a law of control determined by method of modal control and error matrixes is established. The roots of characteristic polynomial are according to the Batterwort's scheme on hemicycle of a given radius even distributed. The results can be used in system design as an alternative option of a law of control determination based on the requirements for accuracy figures.

Keywords: law of control, modal control, stabilization precision.

Для возмущенного движения в одной плоскости с учетом инерции исполнительного устройства установлена связь определенного методом модального управления закона регулирования с матрицами ошибок. Корни характеристического полинома согласно со схемой Баттерворта равномерно размещены на полуокружности заданного радиуса. Результаты могут быть использованы при разработке системы как альтернативный вариант определения закона регулирования, исходя из требований к показателям точности.

Ключевые слова: закон регулирования, модальное управление, точность стабилизации.

Вступ. Систему стабілізації (СС) руху ракети, як і будь-яку автоматичну систему, прийнято розділяти на об'єкт управління і регулятор. Закон регулювання (ЗР) визначає залежність вихідного сигналу регулятора від координат вектора стану. Коли пріоритетним показником СС $\epsilon$ точність, то ЗР розраховується виходячи з іiі кількісних оцінок; а якщо на перше місце ставиться якість перехідного процесу, визначена вибраним критерієм, то для знаходження ЗР можна використати розвинений у роботах О. А. Красовського метод аналітичного конструювання регуляторів.

Одним із варіантів визначення ЗР $\epsilon$ використання методу модального управління, згідно з яким забезпечується задане розташування коренів характеристичного полінома (ХП) і відповідна перехідна функція. Розміщення коренів ХП, згідно 3 Баттервортом, рівномірно на півколі певного радіуса $\epsilon$ доцільним 3 погляду частотної характеристики СС в інтервалі низьких частот, але залишається відкритим питання точності компенсації збурень і вимог до швидкодії виконавчого пристрою (ВП).
Задача роботи - встановлення зв'язку між параметром Баттерворта радіусом півкола на площині коренів ХП і кількісною оцінкою точності компенсації лінійних у часі збурювальних прискорень 3 урахуванням інерції ВП для СС руху в одній площині. Матеріали роботи розширюють методичну базу проектування CC ракет і можуть бути використані як один із варіантів визначення 3Р, спираючись на коефіцієнти рівнянь збуреного руху в околі певної точки траєкторії і вимоги до показників точності.

Огляд літератури. Специфіка ракети як об'єкта управління полягає в широкому протягом польоту діапазоні масовоінерційних характеристик, швидкостей i висоти, а також у наявності коливальних ланок, обумовлених кінцевою жорсткістю корпусу і рухом вільної поверхні компонентів палива $[1 ; 2]$. Коливання рідини в баках або в конструкціях корисного навантаження суттєво ускладнює стабілізацію руху i вимагає спеціальних заходів при розробці проекту, зокрема, раціональний вибір форми баків і установку демпферів [3]. 
Розроблено методику оптимізації ЗР за критерієм «ймовірність стійкості», оскільки параметри ракети відомі з певною похибкою [4]. Її ефективність підтверджено на моделі восьмого порядку, в якій, крім обертального, беруться до уваги рух центра мас, пружність корпусу та динамічні характеристики ВП.

Одним із методів розрахунку коефіцієнтів лінійного ЗР, при яких стає найменшою кількісна оцінка (критерій) якості перехідного процесу компенсації збурень СС, $є$ використання системи нелінійних рівнянь Ріккаті. Для СС плоского обертального руху ракети із врахуванням інерції ВП (порядок моделі чотири) розроблено послідовність встановлення зв'язку між показниками точності і коефіцієнтами якості перехідного процесу. Основні кроки такі: розв'язок 10 нелінійних диференціальних рівнянь Ріккаті, в результаті якого знаходяться чотири коефіцієнти ЗР, i розрахунок векторів помилок при дії лінійного збурювального прискорення [5]. Для моделі СС другого порядку отримано аналітичний розв'язок рівнянь Ріккаті [6] і запропоновано алгоритм визначення елементів симетричної матриці критерію, при яких забезпечуються задані показники СС, зокрема, глобальна стійкість.

Отримано оцінки точності компенсації лінійного збурювального прискорення у вигляді нескладних аналітичних залежностей від параметрів ракети i коефіцієнтів 3Р [7]. Показано можливість компромісного узгодження суперечливих вимог до точності і запасу стійкості. Врахування руху центра мас на перехідних процесах компенсації збурень не проводиться.

Аналіз показує, що в доступних джерелах недостатньо висвітлено показники СC, ЗР якої вибрано методом модального управління, зокрема, 3 використанням стандартних форм Баттерворта [8].

Матеріали і методи. На початковому етапі розробки СС не беруться до уваги осцилятори пружних коливань корпусу ракети та рідкого палива. Тоді в околі певної точки траєкторії збурений рух у площині рискання описується рівнянням:

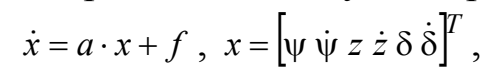

де координатами вектора стану $x \in$ : кут рискання, його похідна за часом, зміщення центра мас перпендикулярно площині траєкторії, його похідна, кут повороту еквівалентного рульового органу та його похідна.В ЗР лінійно входять всі координати вектора стану 3 коефіцієнтами $k_{\psi}, k_{\psi}^{\prime}, k_{z}, k_{z}^{\prime}, k_{\delta}, k_{\delta}^{\prime}$, при цьому:

$$
\begin{gathered}
\boldsymbol{a}=\left[\begin{array}{cccccc}
0 & 1 & 0 & 0 & 0 & 0 \\
\boldsymbol{a}_{\psi \psi} & 0 & 0 & 0 & \boldsymbol{a}_{\psi \delta} & 0 \\
0 & 0 & 0 & 1 & 0 & 0 \\
\boldsymbol{a}_{z \psi} & 0 & 0 & 0 & \boldsymbol{a}_{z \delta} & 0 \\
0 & 0 & 0 & 0 & 0 & 1 \\
\mu \cdot \boldsymbol{k}_{\psi} & \mu \cdot \boldsymbol{k}_{\psi}^{\prime} & -\mu \cdot \boldsymbol{k}_{z} & -\mu \cdot \boldsymbol{k}_{z}^{\prime} & \mu \delta & \mu \cdot \boldsymbol{v}
\end{array}\right], \\
\mu \delta=\mu \cdot\left(k_{\delta}-1\right), \mu=\frac{1}{\mathrm{~T}_{\mathrm{AC}}^{2}}, \nu=k_{\delta}^{\prime}-\xi \cdot T_{A C} \cdot(2)
\end{gathered}
$$

В (2) позначено: $a_{\psi \psi}, a_{\psi \delta}, a_{z \psi}, a_{z \delta}-$ традиційні [2] коефіцієнти, які залежать від параметрів ракети і точки траєкторії; $T_{A C}$, - постійна часу і коефіцієнт демпфування ВП.

Для визначення матриць похибок вектор збурень $f$ напишемо у вигляді:

$$
f=c \cdot w=\left[\begin{array}{ll}
0 & 0 \\
1 & 0 \\
0 & 0 \\
0 & 1 \\
0 & 0 \\
0 & 0
\end{array}\right] \cdot\left[\begin{array}{c}
m_{y} \\
f_{z}
\end{array}\right]=\left[\begin{array}{c}
0 \\
m_{y} \\
0 \\
f_{z} \\
0 \\
0
\end{array}\right] .
$$

Координатами вектора збурень $w(3)$ $\epsilon: \quad m_{y}, f_{z}$ - обертальне та лінійне прискорення, яке може бути викликане аеродинамічними силами, відхиленнями ракети від геометричної та масової симетрії або іншими причинами.

Розміщені на півколі радіусом $\omega_{0}$ (параметр Баттерворта) корені

$$
s_{j}=\omega_{0} \cdot e^{i \cdot\left(\frac{17}{12} \pi-j \cdot \frac{\pi}{6}\right)} ; j=\overline{0,5} ; i^{2}=-1 ;
$$

дають ХП у вигляді [8]:

$$
Q(s)=s^{6}+3.8637 \cdot \omega_{0} \cdot s^{5}+7.4641 \cdot \omega_{0}^{2} \cdot s^{4}+9.14162 \cdot \omega_{0}^{3} \cdot s^{3}+7.4641 \cdot \omega_{0}^{4} \cdot s^{2}+3.8637 \cdot \omega_{0}^{5} \cdot s+\omega_{0}^{6} .
$$


Відповідно (4) дійсна складова найближчого до уявної осі кореня ХП (5) ступінь стійкості $\eta=-\omega_{0} \cdot \cos \left(\frac{17 \pi}{12}\right)=0.259 \cdot \omega_{0}$, частоти коливальних складових у перехідному процесі: $0.259 \omega_{0}, 0.707 \omega_{0}, 0.966 \omega_{0}$.

Залежність коефіцієнтів ЗР від параметра Баттерворта $\omega_{0}$ визначається шляхом прирівнювання множників при відповідних степенях змінної комплексного типу $s$ виразу (5) відповідним величинам ХП, що слідує з матриці $a$ (2):

$$
Q(s)=\operatorname{det}\left(a-s \cdot E_{6}\right)=s^{6}+\sum_{i=0}^{5} q_{i} \cdot s^{i},
$$

де $E_{6}-$ одинична матриця шостого порядку,

$$
\begin{gathered}
q_{0}=\mu \cdot k_{z} \cdot\left(a_{\psi \delta} \cdot a_{z \psi}-a_{\psi \psi} \cdot a_{z \delta}\right)=\mu \cdot k_{z} \cdot g, \\
q_{1}=\mu \cdot k_{z}^{\prime} \cdot g, q_{2}=\mu \delta \cdot a_{\psi \psi}-\mu \cdot k_{\psi} \cdot a_{\psi \delta}+\mu \cdot k_{z} \cdot a_{z \delta}, \\
q_{3}=\mu \cdot v \cdot a_{\psi \psi}-\mu \cdot k_{\psi}^{\prime} \cdot a_{\psi \delta}+\mu \cdot k_{z}^{\prime} \cdot a_{z \delta}, \\
q_{4}=-\mu \delta-a_{\psi \psi}, q_{5}=-\mu \cdot v .
\end{gathered}
$$

В результаті, зберігаючи у множниках дві цифри після коми, отримуємо коефіцієнти ЗР залежно від $\omega_{0}$ :

$$
\begin{gathered}
k_{z}=\frac{\omega_{0}^{6}}{\mu \cdot g}, k_{z}^{\prime}=\frac{3.86 \cdot \omega_{0}^{5}}{\mu \cdot g}, \\
k_{\psi}=\frac{-a_{z \delta} \cdot \omega_{0}^{6}+7.46 \cdot g \cdot \omega_{0}^{2} \cdot\left(\omega_{0}^{2}+a_{\psi \psi}\right)+g \cdot a_{\psi \psi}^{2}}{\mu \cdot\left|a_{\psi \delta}\right| \cdot g}, \\
k_{\psi}^{\prime}=\frac{\omega_{0} \cdot\left(-3.86 \cdot a_{z \delta} \cdot \omega_{0}^{4}+9.13 \cdot g \cdot \omega_{0}^{2}+3.86 g \cdot a_{\psi \psi}\right)}{\mu \cdot\left|a_{\psi \delta}\right| \cdot g}, \\
\boldsymbol{k}_{\delta}=\left(-7.46 \omega_{0}^{2}+\mu-\boldsymbol{a}_{\psi \psi}\right) / \mu, \\
k_{\delta}^{\prime}=\left(\mu \cdot \xi \cdot T_{a c}-3.86 \omega_{0}\right) / \mu .
\end{gathered}
$$

\begin{tabular}{|c|c|c|c|c|c|}
\hline $\boldsymbol{a}_{z \psi}$ & $\boldsymbol{a}_{z \delta}$ & $a_{\psi \psi}$ & $a_{\psi \delta}$ & $\xi$ & $T_{A C}$ \\
\hline \multicolumn{2}{|c|}{$\mathrm{M} / \mathrm{c}^{2}$} & \multicolumn{2}{|c|}{$\mathrm{c}^{-2}$} & - & $\mathrm{c}$ \\
\hline-36.1 & -1.44 & 1.81 & -0.295 & 1.0 & 0.1 \\
\hline
\end{tabular}

Перші чотири коефіцієнти 3Р (7) пропорційні $\omega_{0}$ (табл. 1 ; рис. 1,2 ), в рамках прийнятої моделі СС $(1,2)$ вони обмежені зверху тільки потужністю i швидкодією ВП; $k_{\delta}, k_{\delta}^{\prime}$ обернено пропорційні $\omega_{0}$ (рис. 3).

Приклад коефіцієнтів моделі СС

Таблиця 1

Точність стабілізації при дії лінійного у часі збурення кількісно можна оцінити матрицями похибок er0 i er1. Після закінчення перехідного процесу вектор стану СC

$$
\begin{gathered}
x(t)=e r 0 \cdot w+e r 1 \cdot \dot{w}, w=\left[\begin{array}{l}
m_{y} \\
f_{z}
\end{array}\right]=\left[\begin{array}{c}
m_{0}+\dot{m}_{0} \cdot t \\
f_{z 0}+\dot{f}_{z 0} \cdot t
\end{array}\right], \\
\dot{w}=\left[\begin{array}{c}
\dot{m}_{0} \\
\dot{f}_{z 0}
\end{array}\right],
\end{gathered}
$$$$
\operatorname{er} 0=\frac{1}{g} \cdot\left[\begin{array}{cc}
a_{z \delta} & -a_{\psi \delta} \\
0 & o \\
\frac{1}{k_{z}} \cdot\left[k_{\psi} \cdot a_{z \delta}-\left(k_{\delta}-1\right) \cdot a_{z \psi}\right] & \frac{1}{k_{z}} \cdot\left[\left(k_{\delta}-1\right) \cdot a_{\psi \psi}-k_{\psi} \cdot a_{\psi \delta}\right] \\
0 & 0 \\
-a_{z \psi} & a_{\psi \psi} \\
0 & 0
\end{array}\right] .
$$

$$
\text { er } 0=-a^{-1} \cdot c ; \quad \text { er } 1=-a^{-2} \cdot c .
$$

Елементи матриць $a^{-1}, a^{-2}$ залежно від коефіцієнтів моделі (табл. 1) і ЗР визначаються шляхом нескладних перетворень в аналітичному вигляді. Згідно $3(2 ; 3 ; 6 ; 7)$ матриця похибок
Відповідно до $(8 ; 9)$ після закінчення перехідного процесу вектор стану СС при нульових початкових значеннях і дії тільки постійних прискорень $\boldsymbol{m}_{0}, \boldsymbol{f}_{z 0}$ 
$k_{z}, M^{-1} ; k_{z}, C \cdot M^{-1}$

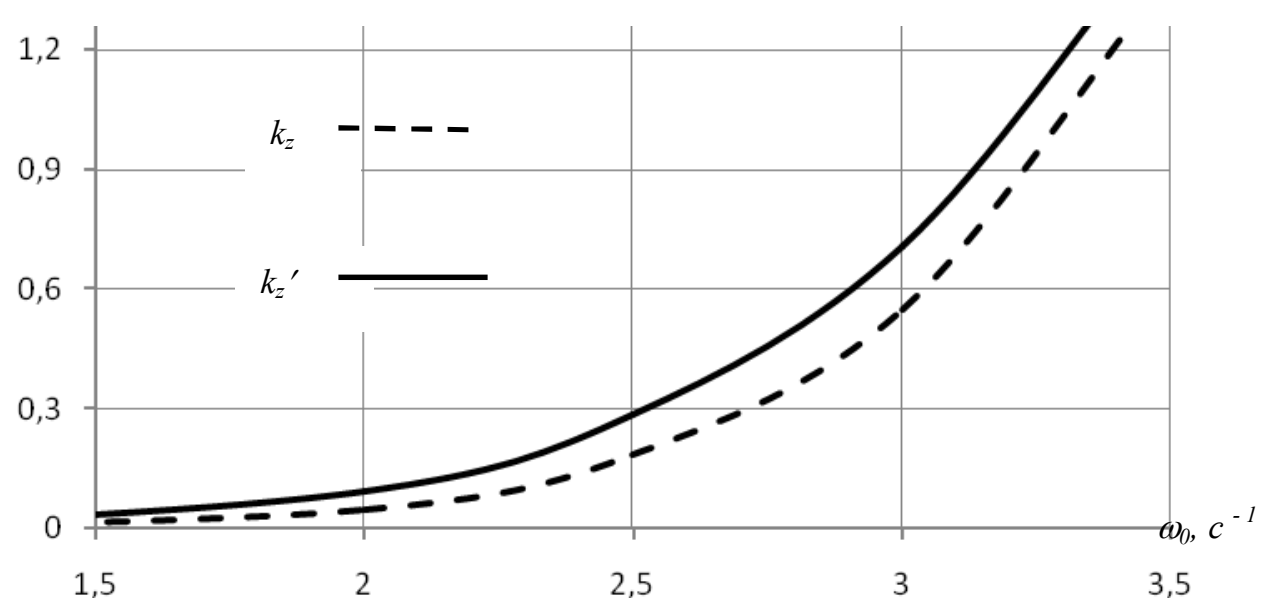

Рис. 1. Коефіціснти 3Р при координаті $z$ вектора стану СС

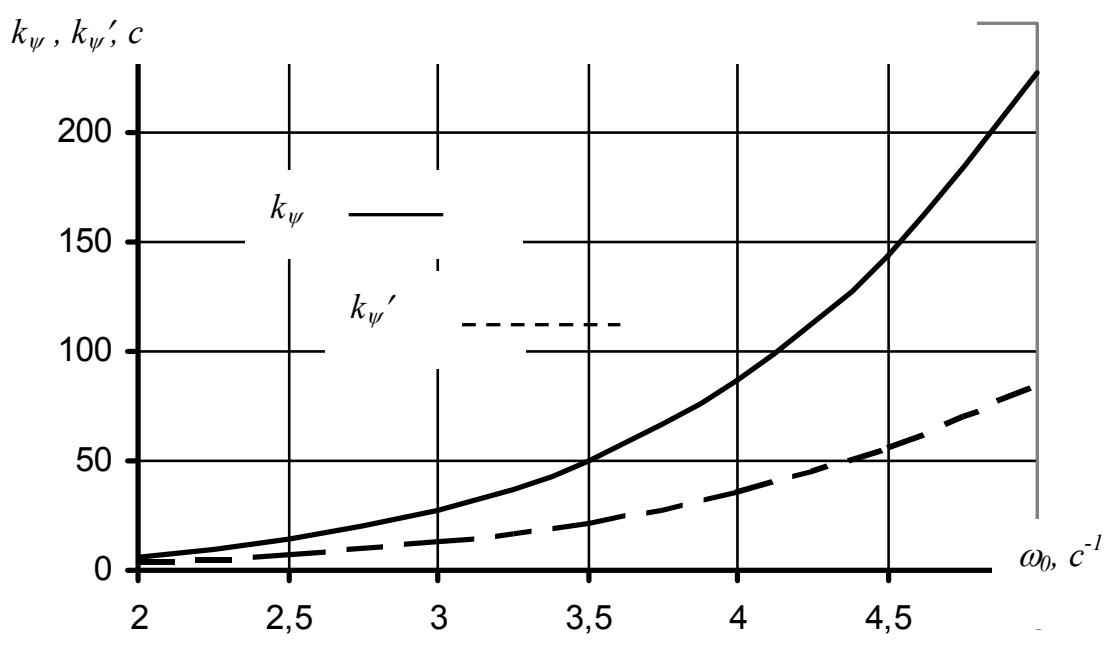

Рис. 2. Коефіщієнти 3Р при координаті $\psi$

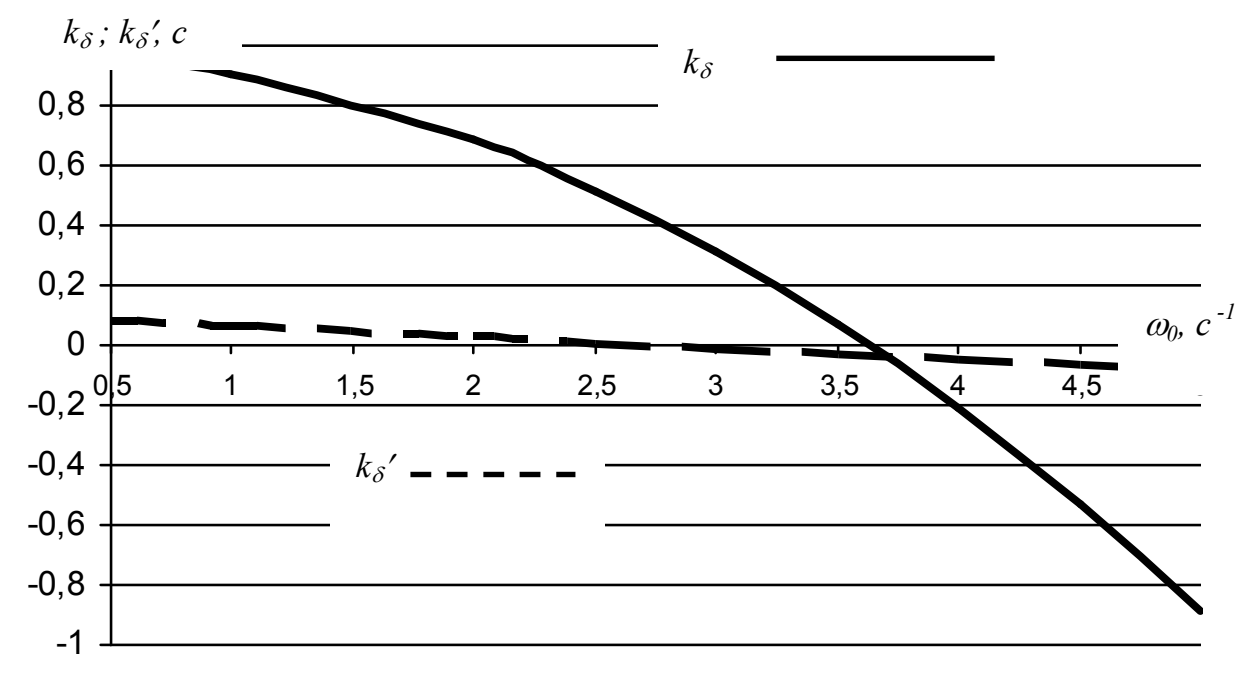

Рис. 3. Коефіцієнти 3Р при координаті $\delta$ 


$$
x=\left[\begin{array}{c}
\psi \\
\dot{\psi} \\
z \\
\dot{z} \\
\delta \\
\dot{\delta}
\end{array}\right]=\frac{1}{g} \cdot\left[\begin{array}{c}
a_{z \delta} \cdot m_{0}-a_{\psi \delta} \cdot f_{z 0} \\
0 \\
\left(\left(\left(1-k_{\delta}\right) \cdot a_{z \psi}+k_{\psi} \cdot a_{z \delta}\right) \cdot m_{0}-f_{z 0} \cdot\left(k_{\psi} \cdot a_{\psi \delta}+a_{\psi \psi} \cdot\left(1-k_{\delta}\right)\right) / k_{z}\right. \\
0 \\
-a_{z \psi} \cdot m_{0}+a_{\psi \psi} \cdot f_{z 0} \\
0
\end{array}\right] .
$$

Коли обертальне збурювальне прискорення створюється проекцією постійної аеродинамічної сили на вісь $z$, то між збуреннями $m_{y}$ i $f_{z}$ має місце лінійна залежність, тобто

$$
m_{y}=m_{0}=f_{z 0} \cdot k_{i}
$$

де $k_{i}$ - коефіцієнт, що залежить від поточних масово-інерційних параметрів ракети.

$$
\begin{gathered}
\mathrm{V}_{0}=-\mathrm{a}_{\mathrm{z \delta}} \cdot\left(1-\mathrm{b} \cdot \mathrm{k}_{\mathrm{i}}\right) / \mathrm{g}, \mathrm{V}_{1}=7.4641 \cdot\left(1-\mathrm{k}_{\mathrm{i}} \cdot \mathrm{b}\right), \mathrm{V}_{2}=7.4641 \cdot \mathrm{k}_{\mathrm{i}} \cdot\left(\mathrm{a}_{\mathrm{z \psi}}-\mathrm{b} \cdot \mathrm{a}_{\psi \psi}\right), \\
\mathrm{V}_{3}=\mathrm{a}_{\psi \psi} \cdot \mathrm{k}_{\mathrm{i}} \cdot\left(\mathrm{a}_{\mathrm{z \psi}}-\mathrm{b} \cdot \mathrm{a}_{\psi \psi}\right), \mathrm{b}=\mathrm{a}_{\mathrm{z} \delta} / \mathrm{a}_{\psi \delta} .
\end{gathered}
$$

Перший доданок (12) залежить тільки від параметрів ракети, які в межах поставленої задачі виражені коефіцієнтами $a_{\psi \psi}, a_{\psi \delta}, a_{z \psi}, a_{z \delta}$. Для даних табл. 1 статична похибка в функції $\omega_{0}$ проходить нульове значення і має слабо виражений екстремум (рис. 4).

$$
z_{r}, c^{2}
$$

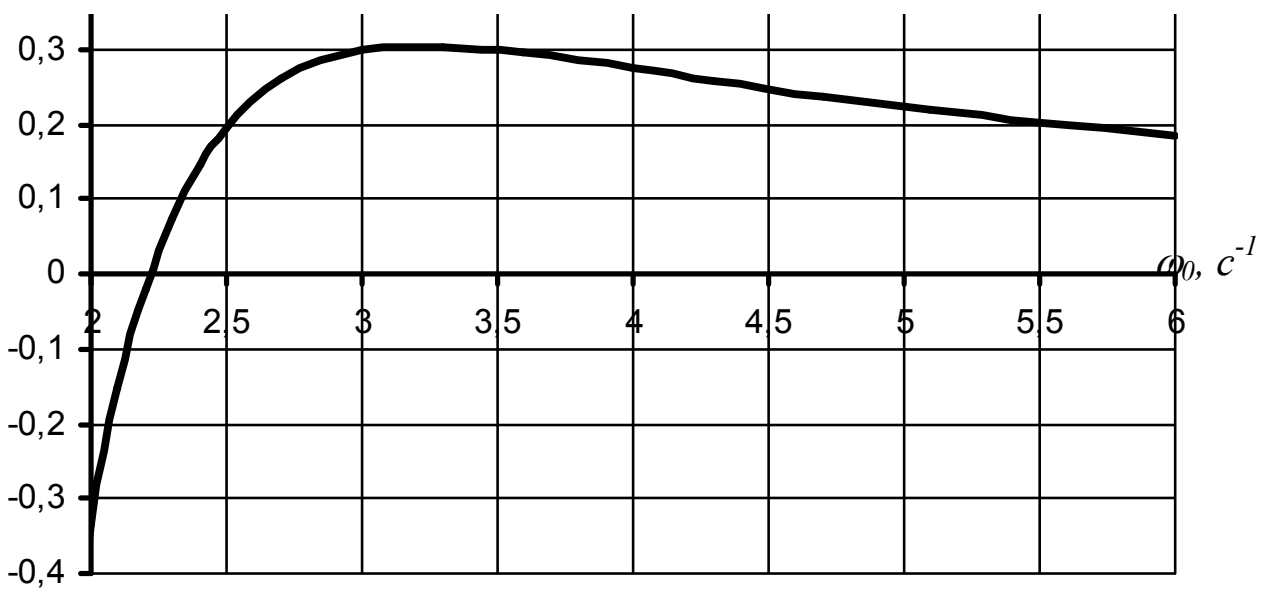

Рис. 4. Статична похибка СС залежно від параметра Баттерворта

Елементи матриці $e r 1, \quad$ яка використовується при розрахунку похибок компенсації лінійного у часі збурення, також можуть бути визначені у функції параметра Баттерворта $\omega_{0}$ :

$$
e r 1=-a^{-2} \cdot c=-\left[\begin{array}{cc}
0 & 0 \\
-a_{z \delta} / g & a_{\psi \delta} / g \\
v_{31} & v_{32} \\
v_{41} & v_{42} \\
0 & 0 \\
a_{z \psi} / g & -a_{\psi \psi} / g
\end{array}\right],
$$

де

$$
v_{31}=\frac{1}{k_{z} \cdot g} \cdot\left[\left(k_{\delta}^{\prime}-\xi \cdot T_{a c}\right) \cdot a_{z \psi}-k_{\psi}^{\prime} \cdot a_{z \delta}+\frac{k_{z}}{k_{z}^{\prime}} \cdot\left(k_{\psi} \cdot a_{z \delta}-\left(k_{\delta}-1\right) \cdot a_{z \psi}\right)\right]=
$$




$$
\begin{gathered}
=\frac{19.69742 \cdot a_{z \delta} \cdot \omega_{0}^{4}-24.97534 \cdot \omega_{0}^{2} \cdot g-3.8637 \cdot a_{\psi \psi} \cdot g}{\left|a_{\psi \delta}\right| \cdot \omega_{0}^{7}}, \\
v_{41}=\frac{\left(k_{\delta}-1\right) \cdot a_{z \psi}-k_{\psi} \cdot a_{z \delta}}{k_{z} \cdot g}=\left(7.4641 \cdot a_{z \delta} / \omega_{0}^{2}-a_{\psi \psi} \cdot g / \omega_{0}^{6}-7.4641 \cdot g / \omega_{0}^{4}-a_{z \delta}^{2} / g\right) / a_{\psi \delta}, \\
v_{42}=\frac{k_{\psi} \cdot a_{\psi \delta}-\left(k_{\delta}-1\right) \cdot a_{\psi \psi}}{k_{z} \cdot g}=\frac{1}{g}\left(a_{z \delta}-\frac{7.4641 \cdot g}{\omega_{0}^{2}}\right), \\
v_{32}=\frac{1}{k_{z} \cdot g} \cdot\left[a_{\psi \delta} \cdot k_{\psi}^{\prime}-v_{42} \cdot g \cdot k_{z}^{\prime}-\left(k_{\delta}^{\prime}-\xi \cdot T_{a c}\right) \cdot a_{\psi \psi}\right]=19.69742 / \omega_{0}^{3} .
\end{gathered}
$$

Відповідно $(8 ; 9 ; 13)$ після закінчення перехідного процесу вектор стану СС при дії лінійного збурення може бути $w(t)=\left[\begin{array}{c}m_{y} \\ f_{z}\end{array}\right]=\left[\begin{array}{c}m_{0}+\dot{m}_{0} \cdot t \\ f_{z 0}+\dot{f}_{z 0} \cdot t\end{array}\right]$ визначений аналітичним виразом

$$
x=\left[\begin{array}{c}
\psi \\
\dot{\psi} \\
z \\
\dot{z} \\
\delta \\
\dot{\delta}
\end{array}\right]=\left[\begin{array}{c}
a_{z \delta} \cdot\left(m_{0}+\dot{m}_{0} \cdot t\right)-a_{\psi \delta} \cdot\left(f_{z 0}+\dot{f}_{z 0} \cdot t\right) \\
a_{z \delta} \cdot \dot{m}_{0}-a_{\psi \delta} \cdot \dot{f}_{z 0} \\
-g \cdot\left[v_{42} \cdot\left(f_{z 0}+\dot{f}_{z 0} \cdot t\right)+v_{41} \cdot\left(m_{0}+\dot{m}_{0} \cdot t\right)+v_{31} \cdot \dot{m}_{0}+v_{32} \cdot \dot{f}_{z 0}\right] \\
-g \cdot\left(v_{42} \cdot \dot{f}_{z 0}+v_{41} \cdot \dot{m}_{0}\right) \\
a_{\psi \psi} \cdot\left(f_{z 0}+\dot{f}_{z 0} \cdot t\right)-a_{z \psi} \cdot\left(m_{0}+\dot{m}_{0} \cdot t\right) \\
a_{\psi \psi} \cdot \dot{f}_{z 0}-a_{z \psi} \cdot \dot{m}_{0}
\end{array}\right] / g .
$$

3 (13; 15) слідує, що від ЗР i, - статична похибка швидкості залежить від відповідно, від параметра Баттерворта $\omega_{0}$ залежать тільки координати $z$ i $\dot{z}$ вектора стану СС. елементів $v_{41}, v_{42}$ матриці (13) обернено пропорційно $\omega_{0} \quad$ (рис. $5, \quad 6$ ).

Після закінчення перехідного процесу при дії збурення (14) модуль координати $\dot{z}$

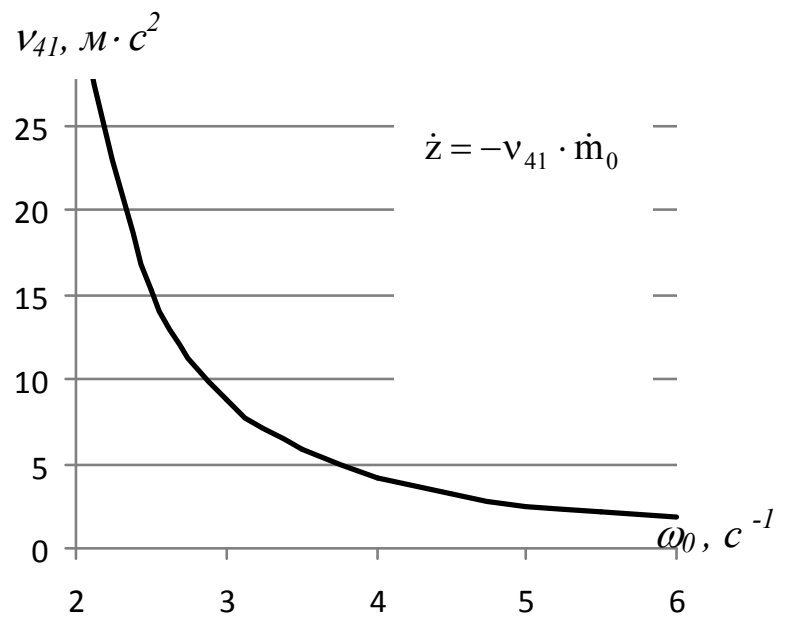

Рис. 5. Статична похибка координати $\dot{Z}$ при дії лінійного у часі обертального збурювального

Результати.

1. Встановлено співвідношення (7) між параметром Баттерворта $\omega_{0}$ i коефіцієнтами ЗР.

2. Визначено залежність елементів матриць похибок (er0,er1) від параметрів ракети, коефіцієнтів ЗР і $\omega_{0}(9 ; 13)$.

3. Для випадку постійного збурювального прискорення від дії аеродинамічної сили встановлено залежність (12, рис. 4) статичної похибки від параметра $\omega_{0}$. 


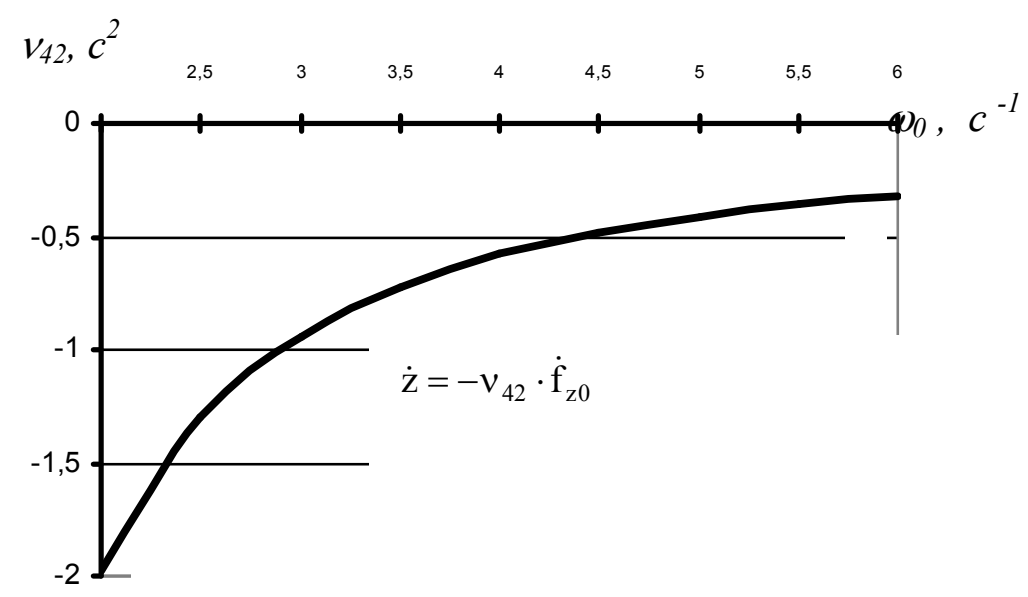

Рис. 6. Статична похибка координати $\dot{z}$ при дії лінійного у часі збурювального прискорення $\mathrm{f}_{\mathrm{z}}$

\section{Висновки.}

1. Коефіцієнти ЗР $k_{\psi}, k_{\psi}^{\prime}, k_{z}, k_{z}^{\prime}$ пропорційні параметру $\omega_{0}$ i в межах прийнятої моделі обмежені зверху тільки потужністю i швидкодією ВП, тоді як коефіцієнти 3Р $k_{\delta}, k_{\delta}^{\prime}$ обернено пропорційні $\omega_{0} .2$. Після закінчення перехідного процесу від коефіцієнтів 3Р i, відповідно, від параметра $\omega_{0}$ залежать тільки координати $z$ і $\dot{z}$ вектора стану CC.

Використання описаного варіанта методу модального управління, в якому задані корені ХП рівномірно розміщені на півколі радіусом $\omega_{0}$, являє собою альтернативну можливість розрахунку ЗР при розробці СС. Недоліком цього підходу, очевидно, слід вважати те, що, на відміну від методу аналітичного конструювання регуляторів, ЗР вибирається без врахування кількісної оцінки якості перехідного процесу, а його перевага в тому, що всі коефіцієнти ЗР і елементи матриць похибок залежать тільки від однієї наперед заданої величини.

\section{Бібліографічні посилання}

1. Колесников К. С. Динамика ракет. Москва : Машиностроение, 1980. 376 с.

2. Dynamic designing of rockets. Dynamics problems of rockets and space stages: monograph / I. M. Igdalov, L. D. Kuchma, N. V. Poliakov, Ju. D. Sheptun; under the editorship by academician
S. N. Konyukchov. Dnipro : ЛIPA, 2013. $280 \mathrm{p}$.

3. Rogers J. Design consideration for stability of liquid payload projectiles. Journal of spacecraft and rockets. No 1. 2013. Vol. 50. P. 169-178.

4. Сухоребрый В. Г., Цветкова А. А., Шопина А. Б. Оптимизация параметров системы стабилизации ракет-носителей с помощью метода вариаций. Открытые информачионные и компьютерные интегрированные технологии. № 68. 2015. C. 5-12. URL: http://nbuv.gov.ua/UJRN/vikt $201568 \quad 3$.

5. Авдєєв В. В. Критерій якості перехідного процесу і показники точності системи стабілізації ракети. Авиационнокосмическая техника и технология. Харьков: ХАИ, 2017. № 1 (136). С. 4-10.

6. Chen C., Liang Y., Jhu W. Global stability of a system with state-dependent Riccati equation controller. Journal of guidance, control, and dynamics. No. 10. 2015. Vol. 38. P. 2050-2054.

7. Авдєєв В. В. Точність і запас стійкості системи стабілізації обертального руху ракети. Радіоелектроніка, інформатика, управління. № 3. 2016. С. 9398.

8. Кузовков Н. Т. Модальное управление и наблюдающие устройства. Москва : Машиностроение, 1976. 184 с.

Надійшла до редколегї 5.06.2018 p. 